\title{
The potential role of testosterone in hypertension and target organ damage in hypertensive postmenopausal women
}

This article was published in the following Dove Press journal:

Clinical Interventions in Aging

\section{Ningyin Li \\ Ruixin Ma \\ Shixiong Wang \\ Yang Zhao \\ Ping Wang \\ Zhitao Yang \\ Lingling Jin \\ Panpan Zhang \\ Hong Ding \\ Feng Bai \\ Jing $Y u$}

Department of Cardiology, Lanzhou University Second Hospital, Lanzhou University, Lanzhou, Gansu 730000,

People's Republic of China
Correspondence: Jing Yu

Department of Cardiology, Lanzhou

University Second Hospital, 82

Cuiyingmen St, Lanzhou, Gansu 730030,

People's Republic of China

Tel +869315190694

Fax +869315190694

Email yujing2304@I26.com
Objective: The aim of this study was to confirm the potential role of testosterone in hypertension and target organ damage (TOD) in hypertensive postmenopausal women.

Methods: A matched group study was conducted. One hundred sixty-one hypertensive postmenopausal women between 45 and 65 years of age were enrolled as group 1. Another 161 age-matched hypertensive men were enrolled as group 2. Ambulatory blood pressure monitoring, echocardiographic imaging, vascular function, sex hormones and clinical characteristics were evaluated. Quantitative data were analyzed using independent Student's $t$-test and multiple regression analysis.

Results: The mean and load level of blood pressure were lower in women than in men $(P<0.05)$, except for the mean level and load of the nocturnal systolic blood pressure (SBP) $(123.77 \pm 15.72 \mathrm{mmHg}$ vs $126.35 \pm 15.64 \mathrm{mmHg}$, and $50.43 \pm 30.31 \%$ vs $55.35 \pm 28.51 \%$, $P>0.05$ ). However, the carotid-femoral pulse wave velocity (cf-PWV) in women was higher than that in men $(9.68 \pm 2.23 \mathrm{~m} / \mathrm{s}$ vs $8.03 \pm 2.82 \mathrm{~m} / \mathrm{s}, P<0.05)$. The ratio of the early diastolic mitral peak flow velocity to early diastolic mitral annular velocity $(\mathrm{E} / \mathrm{Em})$ was obviously impaired $(13.06 \pm 3.53$ vs $12.05 \pm 3.68, P<0.05)$ in women. Furthermore, in women, a positive correlation was found between testosterone and cf-PWV $(\gamma=0.157, P=0.046)$, and Cf-PWV was positively related to the mean level of nighttime SBP $(\gamma=0.210, P=0.008)$. Moreover, nocturnal SBP was a risk factor for $\mathrm{E} / \mathrm{Em}(\gamma=0.156, P=0.048, P<0.05)$.

Conclusion: Testosterone may play a role in the correlation between hypertension and TOD in hypertensive postmenopausal women.

Clinical Trial number: This research study was registered under the ClinicalTrials.gov PRS Website (NCT03451747).

Keywords: postmenopausal women, hypertensive, left ventricular diastolic function, carotid-femoral pulse wave velocity, testosterone

\section{Introduction}

Hypertension, a common chronic condition that affects up to $40 \%$ of human adults, ${ }^{1-3}$ is a major risk factor for stroke, heart attack, and other vascular as well as renal and metabolic diseases. ${ }^{2,4-7}$ Hypertension, which is associated with target organ damage (TOD), ${ }^{8}$ is a serious cause of cardiovascular and cerebrovascular diseases. ${ }^{9}$ As the body ages, blood pressure (BP) tends to increase in both men and women. ${ }^{10-14}$ However, men generally have a higher BP and an increased prevalence of cardiovascular disease (CVD) than age-matched women until after 
menopause, when the phenomenon reverses. ${ }^{10,11,13,15}$ Moreover, the increase in deaths from CVD is generally higher in hypertensive postmenopausal women than in men. ${ }^{16}$ Hypertension is a major risk factor for the excessive morbidity and mortality caused by TOD, ${ }^{8,17}$ such as left ventricular diastolic dysfunction (LVDD), in postmenopausal women. ${ }^{15}$

Menopause is an important change in the estrogen/androgen ratio. The difference in BP between men and women is caused by the protective role of estrogens ${ }^{18}$ or the prohypertensive role of testosterone (T). ${ }^{18}$ Previous studies have found that endogenous estradiol $\left(E_{2}\right)$ may play an important role in lowing $\mathrm{BP},{ }^{19,20}$ reducing the level of inflammation, ${ }^{19}$ preventing endothelial dysfunction, and protecting against cardiovascular tissue remodeling. Therefore, a lack of $E_{2}$ is an important factor in the increased prevalence of CVD and hypertension in postmenopausal women. ${ }^{21,22}$ However, over the past 20 years, the level of total $\mathrm{T}$ has been shown to be a risk factor for SBP and death. ${ }^{23-25}$ Moreover, American women ${ }^{26,27}$ have high serum $\mathrm{T}$ levels, and the frequency of hypertension is increased in this population. ${ }^{28}$ Thus, an imbalance between estrogen and androgen may be an important factor in reversing the prevalence of CVD and hypertension. $^{28,29}$ Therefore, we hypothesize that $\mathrm{T}$ plays a role in hypertension and TOD in hypertensive postmenopausal women. The objective of this work is to evaluate the effects of T on hypertension and TOD in hypertensive postmenopausal women.

\section{Methods}

\section{Study population}

This study is a matched cross-sectional study. The least sample size required was estimated by the formula of independent sample frequency test $\mathrm{N}=\left[\frac{2\left(u_{\alpha}+u_{\beta}\right) \sigma}{\delta}\right]^{2}$. One side was taken as $\mathrm{a}=0.05, \beta=0.10$, and using the look up table, and we obtain $\mathrm{u} \alpha=1.96, \mathrm{u} \beta=1.28$. The related literature was searched, and the maximum value of $\delta(\alpha=1.4)$ and the minimum value of $\delta(\delta=0.63)$ were incorporated into the formula $\mathrm{N}=\left[\frac{2 \times(1.96+1.28) \times 1.91}{0.98}\right]^{2}$. A total of 322 hypertensive patients hospitalized in our department between October 2016 and February 2017 were enrolled. The inclusion criteria were as follows. First, participants were aged between 45 and 65 years. Second, female patients were all postmenopausal women. Third, all patients were diagnosed with essential hypertension according to the Guidelines Prevention and Treatment of Hypertension in China.

This study was conducted in accordance with the Declaration of Helsinki. Only relevant personal and medical information from the patients included in the study were collected. In the study, we fully considered and implemented measures to protect patient privacy, such as replacing the patient's name with a digital code. This study was supported by the youth fund of the "Cuiying science and technology innovation" program of Lanzhou University Second Hospital (CY2017-QN09). This study was approved by the Ethics Committee of Lanzhou University Second Hospital (20101024038). All of the patients signed an informed consent form before any medical information was retrieved.

\section{Clinical and anthropometric measurements}

Clinical characteristics, such as height, weight, BMI, ${ }^{30} \mathrm{BP}$, history of hypertension, family history, anti-hypertensive medication use, and other metabolic indices, were collected.

\section{Clinical chemistry and serum sex hormone levels}

Sex hormone levels including $\mathrm{T}, \mathrm{E}_{2}$, luteinizing hormone (LH), prolactin (PRL), follicle stimulating hormone (FSH) and progesterone $(\mathrm{P})$ were examined by a chemiluminescence immunoassay. ${ }^{31}$

\section{Office BP}

Office BP was measured by certified researchers with an Omron Model M7 digital automatic BP monitor (Omron Healthcare, Inc., Lake Forest, IL). The office BP level was recorded as the mean value of separate readings from the second and third measurements. ${ }^{32}$

\section{Ambulatory blood pressure monitoring (ABPM)}

Noninvasive ABPM was performed for every enrolled patient with ABPM equipment (Spacelabs 90207, Spacelabs, Redmond, WA).

The data from the $24 \mathrm{hrs}$ ABPM measurements were imported using automated software (Shuoyun ABPM remote analysis management software, China, version 1.0) on a computer. ${ }^{33}$ 


\section{Measurement of vascular TOD and central hemodynamics}

A SphygmoCor device (software SphygmoCorCvMS, v8.1; AtCor Medical, Australia) was used to perform measurements on the right side of the body. ${ }^{34,35}$

The augmentation index (AIx) was calculated and expressed as a percentage. ${ }^{36}$ The average value of the two tests were used in subsequent analyses. ${ }^{37}$

Because of the dependence of AIx on heart rate (HR), AIx was normalized to a HR of 75 beats per minute (AIx@HR75). ${ }^{38}$

Cf-PWV was measured by an automatic device (Complior, Artech, France) from SphygmoCor on the right femoral artery and right common carotid artery. ${ }^{39,40} \mathrm{Cf}-\mathrm{PWV}$ was determined according to the pulse transit time divided by the travel distance. ${ }^{41}$ The measurements with an operator index of more than $80 \%$ were accepted and included in the analysis. $^{42}$ According to the present guidelines, ${ }^{1,43,44}$ cfPWV measurements of more than $10 \mathrm{~m} / \mathrm{s}$ were considered to indicate increased arterial stiffness. ${ }^{45}$

\section{Echocardiography}

An echocardiographic examination was performed using a commercially available ultrasound system (Vivid 9, GE Healthcare, Horten, Norway) with a $2.5 \mathrm{MHz}$ transducer.

A 2-dimensional transthoracic echocardiography was performed to assess the LV volume, and the LVDD was calculated. The LV end-diastolic diameter (LVEDd) and end-systolic diameter (LVESd), interventricular septum thickness (IVST), and posterior wall thickness (PWT) were acquired from the parasternal long- and short-axis views using M-mode echocardiography at the level of the mitral valve leaflet tips, according to the recommendations of the American Society of Echocardiography. ${ }^{46}$
The LVMI was calculated as LVM normalized to the body surface area. ${ }^{47}$

Diastolic function was evaluated by pulse wave Doppler recordings during diastole in the apical fourchamber view. $^{48}$

\section{Statistical analysis}

Statistical analysis was performed using the SPSS statistical package (version 23.0; SPSS Inc., Chicago, Illinois, USA). Continuous variables are presented as the mean and standard deviation (SD). The differences in relative indicators between men and women were assessed by independent Student's $t$-test. Multiple linear regression analysis was used to assess the association between different indicators. The above differences were tested by two-way analysis of variance. A $P$-value $<0.05$ was considered statistically significant. And the data sharing statement indicating were shown in Table 1.

\section{Results}

\section{Clinical characteristics}

According to the inclusion and exclusion criteria, 322 patients aged 45-65 years were included in our study, including 161 men and 161 women. Participants in the male and female groups were matched in terms of age, level of BP, blood glucose, blood lipid, history of hypertension and anti-hypertensive medication use.

The main demographic characteristics of 322 individuals are summarized in Table 2 according to sex. The average age of the men was $55.95 \pm 5.89$, which was similar to that of the women $(55.91 \pm 5.89)$. The biochemical parameters showed no differences between the two groups, except for the level of serum creatinine, which was higher in men than in women $(78.77 \pm 11.04 \mu \mathrm{mmol} / \mathrm{L}$ vs 68.14 $\pm 13.92 \mu \mathrm{mmol} / \mathrm{L}, P=0$ ) (Table 2 ). However, the biochemical parameters were within the normal range.

Table I Data sharing statements that fulfill these ICMJE requirements

\begin{tabular}{|l|l|}
$\begin{array}{l}\text { Whether the authors intend to share individual deidentified } \\
\text { participant data? }\end{array}$ & Yes. \\
What data in particular will be shared? & $\begin{array}{l}\text { Individual participant data that underlie the results reported in this article, after } \\
\text { deidentification (text and tables). } \\
\text { Study Protocol and Statistical Analysis Plan. } \\
\text { What other documents will be available? }\end{array}$ \\
$\begin{array}{ll}\text { When will data be available (start and end dates)? } \\
\text { By what mechanism will data be made available? }\end{array}$ & $\begin{array}{l}\text { Proposals may be submitted up to } 36 \text { months following article publication. After } \\
36 \text { months the data will be available in our University's data warehouse but without } \\
\text { investigator support other than deposited metadata. }\end{array}$ \\
\hline
\end{tabular}


Table 2 Comparisons of clinical characteristics and metabolic indexes between two groups $(\mathrm{N}=322)$

\begin{tabular}{|c|c|c|c|}
\hline & Male $(n=\mid 6 I)$ & Female $(n=161)$ & $P$ \\
\hline Age (years) & $55.95 \pm 5.89$ & $55.91 \pm 5.89$ & 0.947 \\
\hline BMI $\left(\mathrm{kg} / \mathrm{m}^{2}\right)$ & $25.75 \pm 2.36$ & $25.20 \pm 2.78$ & 0.052 \\
\hline WBC $\left(\times 10^{9} / \mathrm{L}\right)$ & $6.37 \pm 1.52$ & $6.05 \pm 1.80$ & 0.090 \\
\hline $\operatorname{RBC}\left(\times 10^{12} / \mathrm{L}\right)$ & $4.69 \pm 0.42$ & $4.61 \pm 0.50$ & 0.109 \\
\hline HGB (g/L) & $|38.82 \pm| 4.0 \mid$ & $|36.22 \pm| 4.57$ & 0.104 \\
\hline $\operatorname{PLT}\left(\times 10^{9} / \mathrm{L}\right)$ & $|90.5| \pm 75.1 \mid$ & $188.30 \pm 56.58$ & 0.766 \\
\hline $\mathrm{K}^{+}(\mathrm{mmol} / \mathrm{L})$ & $3.85 \pm 0.46$ & $3.77 \pm 0.38$ & 0.092 \\
\hline $\mathrm{Na}^{+}(\mathrm{mmol} / \mathrm{L})$ & $14 \mid .44 \pm 16.40$ & $141.05 \pm 3.02$ & 0.770 \\
\hline $\mathrm{Cr}(\mu \mathrm{mmol} / \mathrm{L})$ & $78.77 \pm 11.04$ & $68.14 \pm 13.92$ & 0 \\
\hline BUN (mmol/L) & $6.22 \pm 2.12$ & $5.90 \pm 1.36$ & 0.111 \\
\hline $\mathrm{UA}(\mu \mathrm{mmol} / \mathrm{L})$ & $380.78 \pm 93.25$ & $365.63 \pm 53.06$ & 0.074 \\
\hline $\mathrm{TC}(\mathrm{mmol} / \mathrm{L})$ & $4.11 \pm 1.03$ & $4.32 \pm 1.02$ & 0.068 \\
\hline TG (mmol/L) & $1.96 \pm 1.17$ & $1.79 \pm 1.20$ & 0.204 \\
\hline $\mathrm{HDL}(\mathrm{mmol} / \mathrm{L})$ & $1.23 \pm 0.33$ & $1.29 \pm 0.34$ & 0.133 \\
\hline LDL (mmol/L) & $2.21 \pm 0.79$ & $2.36 \pm 0.82$ & 0.082 \\
\hline $\mathrm{GLU}(\mathrm{mmol} / \mathrm{L})$ & $6.87 \pm 0.85$ & $6.93 \pm 0.63$ & 0.259 \\
\hline ALT (U/L) & $37.02 \pm 27.99$ & $31.44 \pm 30.52$ & 0.088 \\
\hline AST (U/L) & $30.14 \pm 22.82$ & $27.16 \pm 17.96$ & 0.195 \\
\hline SBP $(\mathrm{mmHg})$ & $142.24 \pm 19.27$ & $138.47 \pm 17.97$ & 0.070 \\
\hline $\mathrm{DBP}(\mathrm{mmHg})$ & $85.65 \pm 11.98$ & $80.68 \pm \mid 1.62$ & 0 \\
\hline
\end{tabular}

Note: The data are shown as mean \pm SD.

Abbreviations: BMI, body mass index; WBC, white blood cell; RBC, red blood cell; HGB, hemoglobin; PLT, platelet; Cr, creatinine; BUN, blood urea nitrogen; UA, uric acid; TC, total cholesterol; TG, triglyceride; HDL, high-density lipoprotein; LDL, low-density lipoprotein; GLU, glucose; ALT, alanine transaminase; AST, aspartate aminotransferase; SBP, systolic blood pressure; DBP, diastolic blood pressure; SD, standard deviation

Table 3 The characteristics of antihypertensive drugs for all hypertensive patients in this study $(\mathrm{N}=322)$

\begin{tabular}{|l|l|l|l|}
\hline & Male (n= I 6 I) & Female (n= I 6 I) & $P$ \\
\hline ACEI & $54(33.5 \%)$ & $4 I(25.5 \%)$ & 0.112 \\
ARB & $39(24.2 \%)$ & $52(32.3 \%)$ & 0.108 \\
CCB & $55(34.2 \%)$ & $48(30.0 \%)$ & 0.403 \\
Diuretic & $41(25.5 \%)$ & $32(20.0 \%)$ & 0.231 \\
$\beta$-blocker & $37(23.0 \%)$ & $29(18.0 \%)$ & 0.269 \\
ACEI $\pm C C B$ & $19(11.8 \%)$ & $12(7.5 \%)$ & 0.186 \\
ARB $\pm C C B$ & $11(6.8 \%)$ & $6(3.7 \%)$ & 0.213 \\
ACEI \pm Diuretic & $18(11.2 \%)$ & $12(7.5 \%)$ & 0.250 \\
ARB \pm Diuretic & $8(5.0 \%)$ & $14(8.7 \%)$ & 0.185 \\
\hline
\end{tabular}

Note: The data are shown as $\mathrm{n}(\%)$.

Abbreviations: $A C E I$, angiotensin-converting enzyme inhibitor; $A R B$, angiotensin receptor blocker; $\mathrm{CCB}$, calcium channel blocker.

In detail, patients in both of the groups were treated with the antihypertensive medications, including angiotensin-converting enzyme inhibitors (ACEI), angiotensin receptor blocker (ARB), $\beta$-blocker, calcium channel blockers (CCB), diuretic and the combination on ACEI or ARB with CCB or diuretic (Table 3).
Table 4 Comparisons of sex hormone levels between two groups $(\mathrm{N}=322)$

\begin{tabular}{|c|c|c|c|}
\hline & $\begin{array}{l}\text { Male } \\
(n=161)\end{array}$ & $\begin{array}{l}\text { Female } \\
(n=161)\end{array}$ & $P$ \\
\hline PRL (ng/ml) & $8.50 \pm 3.31$ & $|5.69 \pm 9.8|$ & 0 \\
\hline FSH (mlU/ml) & $6.15 \pm 3.12$ & $43.94 \pm|8.4|$ & 0 \\
\hline $\mathrm{LH}(\mathrm{mlU} / \mathrm{ml})$ & $4.85 \pm 2.51$ & $28.46 \pm 11.97$ & 0 \\
\hline $\mathrm{E}_{2}(\mathrm{pg} / \mathrm{ml})$ & $33.79 \pm 12.59$ & $30.95 \pm 24.12$ & 0.186 \\
\hline Testosterone (ng/dl) & $404.22 \pm 137.43$ & $36.22 \pm 15.09$ & 0 \\
\hline Progesterone $(\mathrm{ng} / \mathrm{ml})$ & $0.38 \pm 0.21$ & $0.37 \pm 0.26$ & 0.714 \\
\hline
\end{tabular}

Note: The data are shown as mean \pm SD.

Abbreviations: PRL, prolactin; $\mathrm{FSH}$, follicle stimulating hormone; $\mathrm{LH}$, luteinizing hormone; $E_{2}$, estradiol; SD, Standard deviation.

\section{Sex hormone levels}

PRL, FSH and LH in the female group were higher than those in the male group (Table 4). Male patients had higher levels of $\mathrm{T}$ than did female subjects.

\section{Twenty-four-hour ABPM}

The mean level and load of $24 \mathrm{hrs}$ BP, daytime BP and nighttime DBP of males were higher $(P<0.05)$ (Table 4$)$. However, these differences disappeared when comparing the mean level and load of nighttime SBP between the different sexes. This finding indicates that the nighttime SBP of female patients did not decrease (Table 5).

\section{Comparison of the cardiovascular ultrasound parameters}

Male patients had significantly higher left atrial diameter (LAD), LVEDd, IVST and LVM values than women (Table 6).

Male subjects had higher LVEDV, LVESV and stroke volume (SV) than women (Table 6).

When cardiovascular diastolic function was analyzed, $\mathrm{E} / \mathrm{Em}$ was higher in women than in men (Table 6).

\section{Vascular indices of organ damage}

Women had higher AIx, AIx@HR75 and PWV values than men, while the central DBP in women was lower than that in men (Table 7).

\section{Multiple linear regression analysis}

$\mathrm{T}$ was positively and independently correlated with PWV values in female patients but not in male patients $(\gamma=0.157$, $P=0.046$ ) (Table 8).

A strong positive correlation was found between PWV and mean nighttime SBP $(\gamma=0.210, P=0.008)$. Moreover, 
Table 5 Comparisons of ambulatory blood pressure monitoring characteristics between two groups $(\mathrm{N}=322)$

\begin{tabular}{|c|c|c|c|}
\hline & Male $(n=161)$ & Female $(n=161)$ & $P$ \\
\hline 24h-mean-SBP (mmHg) & $134.76 \pm 16.58$ & $128.09 \pm 14.23$ & 0 \\
\hline 24h-mean-DBP (mmHg) & $80.53 \pm 10.38$ & $75.63 \pm 7.79$ & 0 \\
\hline daytime-mean-SBP $(\mathrm{mmHg})$ & $138.19 \pm 16.93$ & $|30.97 \pm| 4.67$ & 0 \\
\hline daytime-mean-DBP $(\mathrm{mmHg})$ & $83.12 \pm 10.63$ & $77.89 \pm 7.97$ & 0 \\
\hline nighttime-mean-SBP $(\mathrm{mmHg})$ & $126.35 \pm 15.64$ & $123.77 \pm 15.72$ & 0.140 \\
\hline nighttime-mean-DBP $(\mathrm{mmHg})$ & $75.93 \pm 10.77$ & $72.33 \pm 9.52$ & 0.002 \\
\hline $24 \mathrm{~h}$ load of SBP (\%) & $51.84 \pm 26.86$ & $42.67 \pm 26.92$ & 0.002 \\
\hline $24 \mathrm{~h}$ load of DBP (\%) & $49.24 \pm 25.53$ & $36.70 \pm 22.35$ & 0 \\
\hline daytime load of SBP (\%) & $49.99 \pm 27.54$ & $41.06 \pm 27.06$ & 0.004 \\
\hline daytime load of DBP (\%) & $45.03 \pm 26.85$ & $29.85 \pm 20.90$ & 0 \\
\hline nighttime load of -SBP (\%) & $55.35 \pm 28.51$ & $50.43 \pm 30.31$ & 0.135 \\
\hline nighttime load of DBP (\%) & $57.69 \pm 27.26$ & $50.44 \pm 29.70$ & 0.023 \\
\hline $24 \mathrm{~h}$ variation of SBP (\%) & $|3.4| \pm 4.29$ & $14.67 \pm 4.67$ & 0.012 \\
\hline $24 \mathrm{~h}$ variation of DBP (\%) & $14.48 \pm 3.92$ & $|5.24 \pm 3.9|$ & 0.083 \\
\hline daytime variation of SBP (\%) & $13.05 \pm 4.29$ & $14.20 \pm 4.77$ & 0.024 \\
\hline daytime variation of DBP (\%) & $13.94 \pm 4.38$ & $14.74 \pm 4.74$ & 0.118 \\
\hline nighttime variation of SBP (\%) & $12.58 \pm 4.98$ & $|3.54 \pm 5.2|$ & 0.094 \\
\hline nighttime variation of DBP (\%) & $13.54 \pm 4.70$ & $14.49 \pm 5.18$ & 0.087 \\
\hline
\end{tabular}

Note: The data are shown as mean \pm SD.

Abbreviations: SBP, systolic blood pressure; DBP, diastolic blood pressure; SD, standard deviation.

Table 6 Comparisons of cardiac structure and function between two groups $(N=322)$

\begin{tabular}{|c|c|c|c|}
\hline & Male $(n=|6|)$ & Female $(n=161)$ & $P$ \\
\hline LAD (mm) & $34.37 \pm 5.58$ & $31.50 \pm 4.6 \mathrm{I}$ & 0 \\
\hline LVEDd (mm) & $48.17 \pm 5.14$ & $46.61 \pm 4.81$ & 0.005 \\
\hline IVST (mm) & $9.01 \pm 1.49$ & $8.58 \pm 1.52$ & 0.011 \\
\hline PWT (mm) & $8.93 \pm 1.33$ & $8.90 \pm 1.28$ & 0.821 \\
\hline LVEDV (ml) & $111.13 \pm 28.56$ & $95.46 \pm 25.13$ & 0 \\
\hline LVESV (ml) & $39.39 \pm 17.22$ & $30.7 I \pm 13.45$ & 0 \\
\hline SV (ml) & $70.93 \pm 14.92$ & $64.95 \pm 14.82$ & 0 \\
\hline EF (\%) & $64.89 \pm 9.14$ & $66.04 \pm 6.33$ & 0.191 \\
\hline FS (\%) & $36.18 \pm 7.22$ & $37.50 \pm 5.39$ & 0.063 \\
\hline $\mathrm{CO}(\mathrm{L} / \mathrm{min})$ & $5.00 \pm 1.25$ & $4.74 \pm 1.11$ & 0.053 \\
\hline $\operatorname{LVM}(\mathrm{g})$ & $172.54 \pm 44.08$ & $|56.8| \pm 4 \mid .54$ & 0.001 \\
\hline RWT & $0.38 \pm 0.07$ & $0.38 \pm 0.07$ & 0.807 \\
\hline LVMI $\left(g / \mathrm{m}^{2}\right)$ & $90.83 \pm 24.33$ & $92.22 \pm 24.19$ & 0.607 \\
\hline$E(\mathrm{~m} / \mathrm{s})$ & $0.73 \pm 0.13$ & $0.75 \pm 0.16$ & 0.131 \\
\hline$A(\mathrm{~m} / \mathrm{s})$ & $0.82 \pm 0.17$ & $0.83 \pm 0.18$ & 0.395 \\
\hline E/A & $0.97 \pm 0.62$ & $0.95 \pm 0.32$ & 0.700 \\
\hline $\operatorname{Em}(\mathrm{m} / \mathrm{s})$ & $0.06 \pm 0.02$ & $0.06 \pm 0.02$ & 0.057 \\
\hline $\operatorname{Am}(\mathrm{m} / \mathrm{s})$ & $0.10 \pm 0.02$ & $0.09 \pm 0.02$ & 0.076 \\
\hline $\mathrm{Em} / \mathrm{Am}$ & $0.67 \pm 0.16$ & $0.67 \pm 0.21$ & 0.752 \\
\hline $\mathrm{E} / \mathrm{Em}$ & $12.05 \pm 3.68$ & $13.06 \pm 3.53$ & 0.012 \\
\hline
\end{tabular}

Note: The data are shown as mean \pm SD.

Abbreviations: LAD, left atrial diameter; LVEDd, left ventricular end-diastolic dimension; IVST, interventricular septal thickness; PWT, left ventricular posterior wall thickness; LVEDV, left ventricular end-diastolic volume; LVESV, left ventricular end-systolic volume; SV, stroke volume; EF, ejection fraction; FS, fractional shortening; LVM, left ventricular mass; RWT, relative wall thickness; LVMI, left ventricular mass index; E, early diastolic mitral peak flow velocity; A, late diastolic mitral peak flow velocity; Em, early diastolic mitral annular velocity; Am, late diastolic mitral annular velocity; SD, standard deviation. 
Table 7 Comparisons of central hemodynamics and vascular function between two groups $(\mathrm{N}=322)$

\begin{tabular}{|l|l|l|l|}
\hline & $\begin{array}{l}\text { Male } \\
(\mathbf{n = 1 6 1 )}\end{array}$ & $\begin{array}{l}\text { Female } \\
(\mathbf{n = 1 6} \text { I) }\end{array}$ & $\boldsymbol{P}$ \\
\hline CAP (mmHg) & $12.35 \pm 5.28$ & $13.14 \pm 4.97$ & 0.172 \\
Alx & $30.07 \pm 8.32$ & $32.49 \pm 9.09$ & 0.013 \\
Alx@HR75 & $28.00 \pm 8.32$ & $31.81 \pm 7.52$ & 0 \\
$\begin{array}{l}\text { Central-SBP } \\
\text { (mmHg) }\end{array}$ & $133.94 \pm 17.84$ & $130.37 \pm 16.88$ & 0.066 \\
$\begin{array}{l}\text { Central-DBP } \\
\text { (mmHg) } \\
\text { cf-PWV (m/s) }\end{array}$ & $85.36 \pm 12.19$ & $80.53 \pm 10.70$ & 0 \\
HR (bpm) & $8.03 \pm 2.82$ & $9.68 \pm 2.23$ & 0 \\
\hline
\end{tabular}

Note: The data were shown as mean \pm SD.

Abbreviations: CAP, central aortic pressure; HR, heart rate; Alx, augmentation index; Alx@HR75, Alx was normalized to a HR of 75 beats per minute; SBP, systolic blood pressure; DBP, diastolic blood pressure; cf-PWV, carotid-femoral pulse wave velocity; bpm, beats per minute; SD, standard deviation.

Table 8 The correlation ship between testosterone and TOD $(\mathrm{N}=322)$

\begin{tabular}{|l|l|l|}
\hline & $\gamma$ & $P$ \\
\hline $\begin{array}{l}\text { cf-PWV } \\
\text { testosterone } \\
\text { nighttime-mean-SBP } \\
\text { cf-PWV } \\
\begin{array}{l}\text { E/Em } \\
\text { nighttime-mean-SBP }\end{array}\end{array}$ & 0.157 & 0.046 \\
\hline
\end{tabular}

Abbreviations: cf-PWV, carotid-femoral pulse wave velocity; SBP, systolic blood pressure; E/Em, the ratio of early diastolic mitral peak flow velocity to early diastolic mitral annular velocity; TOD, target organ damage.

nocturnal SBP was a risk factor for $\mathrm{E} / \mathrm{Em}$ values $(\gamma=0.156$, $P=0.048$ ) (Table 8).

\section{Discussion and conclusion}

According to the results of this study, BP was lower in hypertensive postmenopausal women than in men. However, this trend disappeared for nighttime SBP. Moreover, atherosclerosis in hypertensive postmenopausal women was significantly higher than that in men. Furthermore, LVDD in hypertensive female patients was significantly worse than that in male patients. $E_{2}$ has been reported to protect against hypertension in postmenopausal women. ${ }^{49}$

Other research has suggested that signs and symptoms of hypertension mostly occurred after TOD. ${ }^{50}$ Moreover, atherosclerosis is the major cause of CVD and one of the main pathological mechanisms of hypertension. ${ }^{51}$ Other studies have suggested that higher BP in hypertensive patients during the night might lead to greater endothelial damage.
Furthermore, greater endothelial damage would lead to higher levels of nocturnal BP. ${ }^{4,49}$ Isolated nighttime hypertension might predict cardiovascular events. ${ }^{52}$ Moreover, the lack of decline in nocturnal BP has been confirmed to be a crucial risk factor in atherosclerosis. ${ }^{2,53}$ Epidemiological studies have suggested that hypertensive men have a higher risk for CVD than age-matched women, ${ }^{11,13}$ but this phenomenon is less stratified after menopause. ${ }^{22,53}$ The difference of risk for CVD may be attributed to the protective effect of estrogen and the harmful effect of androgens. ${ }^{54}$ Some research has shown that androgen withdrawal is positively correlated with arterial stiffness and the risk of CVD in male patients. ${ }^{15}$ However, other studies have shown the opposite effect that $\mathrm{T}$ has protective effects on the cardiovascular system and other target organs. ${ }^{55}$

Due to the effects of T on blood lipid metabolism, it exerts opposite effects in men and women. T plays a favorable role in men but may be harmful to women. These effects of $\mathrm{T}$ are based on its binding to the relevant receptors. Androgen receptors have been shown to be distributed in vascular smooth muscle and endothelial cells, ${ }^{56}$ which may be the reason for the differential effects of $T$ on endothelial function and nocturnal SBP observed in this study. However, when the concentrations of $\mathrm{T}$ are at physiological values, $\mathrm{T}$ can increase the endothelial synthesis of NO through several pathways and can also directly enhance NO production in endothelial cells. ${ }^{57}$ In women, $\mathrm{T}$ is synthesized by theca cells in the ovary, placenta, and adrenal cortex. ${ }^{58}$ Previous studies have suggested that both $\mathrm{T}$ and estrogen influence endothelial function by modulating NO release. ${ }^{22}$ Moreover, the exact mechanisms of modulating endothelial function may involve activated Akt and MAPK pathways. ${ }^{59}$ Although an abrupt decrease in estrogen occurs in women after menopause, the level of $\mathrm{T}$ in men gradually decreases by approximately $1-2 \%$ every year in early adulthood. ${ }^{60,61}$ Another prospective observational study demonstrated that a low level of $\mathrm{T}$ was associated with an increased risk of mortality for male patients. ${ }^{23}$ It is well known that approximately $15-25 \%$ of men over 50 years old have lower levels of $\mathrm{T}$ than men younger than 50 years old. ${ }^{62}$ Although the level of $\mathrm{T}$ in men is approximately 10 times that in women, women are more sensitive to $\mathrm{T}^{58}$ According to the abovementioned differences in physiological changes from sexual hormones and the distinct trends in nocturnal SBP in male and female hypertensive patients, $T$ might play a role in the divergent relationship between nighttime SBP and TOD. For postmenopausal women, the level of reactive oxygen species (ROS) increases significantly. Research has also demonstrated that $\mathrm{T}$ can promote the generation of ROS, 
which decreases NO bioavailability for vasodilation. ${ }^{63}$ Substantial data support the idea that $\mathrm{T}$ positively mediates vasoconstriction. $^{64}$

Taken together, testosterone levels in men and women are very different. In men, high levels of testosterone have protective effects such as vasodilation, but these are diminished as testosterone levels decline with age. For postmenopausal women, although the testosterone level is very low, it is slightly higher than that before menopause, which leads to TOD. Therefore, we hypothesized that testosterone binds to different receptors and works through different mechanisms in men and women. Thus, testosterone should be one of the key factors analyzed in future works investigating the damage to and protection of target organs in hypertensive postmenopausal women.

Previous studies have demonstrated the importance of monitoring daytime and nighttime BP, which are risk factors for cardiovascular mortality and other TOD. ${ }^{47,65}$ Therefore, the decrease in mean BP-values during sleep by ABPM may be the only factor - or the most important factor - that can provide information for clinical treatment for and prediction of TOD. ${ }^{66-68}$ A decrease in nocturnal BP of less than $10 \%$ is considered nondipping, which is observed frequently in postmenopausal women. ${ }^{33}$ In hypertensive postmenopausal women, increased levels of T, ROS and inflammation, which were confirmed to be associated with the nondipping pattern, could lead to endothelial dysfunction. ${ }^{69}$ Although previous studies have indicated that $\mathrm{T}$ has vasodilating properties, this positive effect is attenuated by its atherogenic effect. As noted in vitro experiments, $\mathrm{T}$ may increase the adhesion of monocytes to the vascular endothelium. In addition, $\mathrm{T}$ has been shown to have an opposite effect on estrogen in the cardiovascular system. Androgens can further exert endothelial dysfunction by regulating the renin-angiotensin system. ${ }^{70}$ Higher $\mathrm{T}$ levels in men and higher $\mathrm{E}_{2}$ levels in women are considered to be key factors in CVD. ${ }^{71}$ Furthermore, endothelial damage causes higher BP during sleep. ${ }^{50,72}$ It has also been suggested that there is an independent association between higher nighttime SBP and early-stage atherosclerosis. ${ }^{73}$

Based on the results of this study, the cardiac structure of hypertensive postmenopausal women was different from that of age-matched hypertensive men, even though their cardiac systolic function was similar. The cardiac diastolic function of female patients was significantly worse than that of male patients. According to the analyses, we found that decreases in nocturnal SBP and PWV were risk factors for left ventricular diastolic function in hypertensive postmenopausal women and that $\mathrm{T}$ was positively correlated with nocturnal SBP and the degree of atherosclerosis. Therefore, we speculate that $\mathrm{T}$ plays a role in hypertension and TOD in hypertensive postmenopausal women.

\section{Limitations}

This is a cross-sectional study that neither considers the timing of exposure and outcomes nor examines the causal relationship between exposure and outcomes. As it is a convenience sample and it is not representative, the findings are not conclusive.

\section{Disclosure}

The authors report no conflicts of interest related to this study.

\section{References}

1. Laurent S, Cockcroft J, Van Bortel L, et al. Expert consensus document on arterial stiffness: methodological issues and clinical applications. Eur Heart J. 2006;27(21):2588-2605. doi:10.1093/eurheartj/eh1254

2. Hermida RC. Sleep-time ambulatory blood pressure as a prognostic marker of vascular and other risks and therapeutic target for prevention by hypertension chronotherapy: rationale and design of the Hygia Project. Chronobiol Int. 2016;33(7):906-936. doi:10.1080/ 07420528.2016.1181078

3. Giles TD, Sander GE, Nossaman BD, et al. Impaired vasodilation in the pathogenesis of hypertension: focus on nitric oxide, endothelial-derived hyperpolarizing factors, and prostaglandins. J Clin Hypertens (Greenwich). 2012;14(4):198-205. doi:10.1111/ j.1751-7176.2012.00606.x

4. Cimen T, Bilgin M, Akyel A, et al. Endocan and non-dipping circadian pattern in newly diagnosed essential hypertension. Korean Circ J. 2016;46(6):827-833. doi:10.4070/kcj.2016.46.6.827

5. Hermida RC, Smolensky MH, Ayala DE, et al. 2013 Ambulatory blood pressure monitoring recommendations for the diagnosis of adult hypertension, assessment of cardiovascular and other hypertension-associated risk, and attainment of therapeutic goals (summary). Joint recommendations from the International Society for Chronobiology (ISC), American Association of Medical Chronobiology and Chronotherapeutics (AAMCC), Spanish Society of Applied Chronobiology, Chronotherapy, and Vascular Risk (SECAC), Spanish Society of Atherosclerosis (SEA), and Romanian Society of Internal Medicine (RSIM). Clin Investig Arterioscler. 2013;25(2):74-82. doi:10.1016/j.arteri.2013.03.002

6. Mancia G, Fagard R, Narkiewicz K, et al. 2013 ESH/ESC Guidelines for the management of arterial hypertension: the Task Force for the management of arterial hypertension of the European Society of Hypertension (ESH) and of the European Society of Cardiology (ESC). $\quad J$ Hypertens. 2013;31(7):1281-1357. doi:10.1097/01. hjh.0000431740.32696.cc

7. Piper MA, Evans CV, Burda BU, et al. Diagnostic and predictive accuracy of blood pressure screening methods with consideration of rescreening intervals: a systematic review for the U. S. Preventive Services Task Force. Ann Intern Med. 2015;162(3):192-204. doi:10.7326/M14-1539

8. Chen Y, Liu JH, Zhen Z, et al. Assessment of left ventricular function and peripheral vascular arterial stiffness in patients with dipper and non-dipper hypertension. $J$ Investig Med. 2018;66(2):319-324. doi:10.1136/jim-2017-000513 
9. Abdalla M. ambulatory blood pressure monitoring: a complementary strategy for hypertension diagnosis and management in low-income and middle-income countries. Cardiol Clin. 2017;35(1):117-124. doi:10.1016/j.ccl.2016.08.012

10. Vermeulen A, Verdonck L, Kaufman JM. A critical evaluation of simple methods for the estimation of free testosterone in serum. J Clin Endocrinol Metab. 1999;84(10):3666-3672. doi:10.1210/ jcem.84.10.6079

11. Alberti KG, Eckel RH, Grundy SM, et al. Harmonizing the metabolic syndrome: a joint interim statement of the International Diabetes Federation Task Force on Epidemiology and Prevention; National Heart, Lung, and Blood Institute; American Heart Association; World Heart Federation; International Atherosclerosis Society; and International Association for the Study of Obesity. Circulation. 2009;120 (16):1640-1645. doi:10.1161/CIRCULATIONAHA.109.192644

12. Cebeci F, Onsun N, Mert M. Insulin resistance in women with hirsutism. Arch Med Sci. 2012;8(2):342-346. doi:10.5114/aoms.2012.28563

13. Cifkova R, Pitha J, Lejskova M, et al. Blood pressure around the menopause: a population study. $J$ Hypertens. 2008;26 (10):1976-1982. doi:10.1097/HJH.0b013e32830b895c

14. Olszanecka A, Dragan A, Kawecka-Jaszcz K, et al. Influence of metabolic syndrome and its components on subclinical organ damage in hypertensive perimenopausal women. Adv Med Sci. 2014;59 (2):232-239. doi:10.1016/j.advms.2013.12.002

15. Olszanecka A, Kawecka-Jaszcz K, Czarnecka D. Association of free testosterone and sex hormone binding globulin with metabolic syndrome and subclinical atherosclerosis but not blood pressure in hypertensive perimenopausal women. Arch Med Sci. 2016;12 (3):521-528. doi:10.5114/aoms.2016.59925

16. Santos RL, Marin EB, Goncalves WL, et al. Sex differences in the coronary vasodilation induced by 17 beta-oestradiol in the isolated perfused heart from spontaneously hypertensive rats. Acta Physiol (Oxf). 2010;200(3):203-210. doi:10.1111/j.1748-1716.2010.02140.x

17. Kivrak A, Ozbicer S, Kalkan GY, et al. Morning blood pressure surge and arterial stiffness in newly diagnosed hypertensive patients. Blood Press. 2017;26(3):181-190. doi:10.1080/ 08037051.2017.1278678

18. Heylen E, Huang A, Sun D, et al. Nitric oxide-mediated dilation of arterioles to intraluminal administration of aldosterone. J Cardiovasc Pharmacol. 2009;54(6):535-542. doi:10.1097/FJC.0b013e31 $81 \mathrm{bfb} 00 \mathrm{~d}$

19. Hernandez I, Delgado JL, Diaz J, et al. 17beta-estradiol prevents oxidative stress and decreases blood pressure in ovariectomized rats. Am J Physiol Regul Integr Comp Physiol. 2000;279(5):R1599_ R1605. doi:10.1152/ajpregu.2000.279.5.R1599

20. Xu X, Xiao JC, Luo LF, et al. Effects of ovariectomy and 17beta-estradiol treatment on the renin-angiotensin system, blood pressure, and endothelial ultrastructure. Int J Cardiol. 2008;130 (2):196-204. doi:10.1016/j.ijcard.2007.08.041

21. Penaherrera CA, Penaherrera R, Duarte MC, et al. Assessment of arterial stiffness in patients with metabolic syndrome in Ecuador: a cross-sectional study. Diabetes Metab Syndr. 2017;11(3):199-202. doi:10.1016/j.dsx.2016.09.006

22. Borgo MV, Claudio ER, Silva FB, et al. Hormonal therapy with estradiol and drospirenone improves endothelium-dependent vasodilation in the coronary bed of ovariectomized spontaneously hypertensive rats. Braz J Med Biol Res. 2016;49(1):e4655. doi:10.1590/ 1414-431X20154655

23. Vlachopoulos $\mathrm{C}$, Pietri P, Ioakeimidis $\mathrm{N}$, et al. Inverse association of total testosterone with central haemodynamics and left ventricular mass in hypertensive men. Atherosclerosis. 2016;250:57-62. doi:10.1016/j.atherosclerosis.2016.04.018

24. English KM, Jones RD, Jones TH, Morice AH, Channer KS. Testosterone acts as a coronary vasodilator by a calcium antagonistic action. $J$ Endocrinol Invest. 2002;25(5):455-458. doi:10.1007/ BF03344037
25. Kupelian V, Hayes FJ, Link CL, et al. Inverse association of testosterone and the metabolic syndrome in men is consistent across race and ethnic groups. J Clin Endocrinol Metab. 2008;93(9):3403-3410. doi: $10.1210 /$ jc. $2008-0054$

26. Falkner B, Sherif K, Sumner A, et al. Hyperinsulinism and sex hormones in young adult African Americans. Metabolism. 1999;48 (1):107-112.

27. Huisman HW, Schutte AE, Van Rooyen JM, et al. The influence of testosterone on blood pressure and risk factors for cardiovascular disease in a black South African population. Ethn Dis. 2006;16 (3):693-698.

28. Chinnathambi V, Balakrishnan M, Yallampalli C, et al. Prenatal testosterone exposure leads to hypertension that is gonadal hormone-dependent in adult rat male and female offspring. Biol Reprod. 2012;86(5):137,1-7. doi:10.1095/biolreprod.111.097550

29. Acromite MT, Mantzoros CS, Leach RE, et al. Androgens in preeclampsia. Am J Obstet Gynecol. 1999;180(1 Pt 1):60-63.

30. Vilela-Martin JF, Giollo-Junior LT, Chiappa GR, et al. Effects of transcutaneous electrical nerve stimulation (TENS) on arterial stiffness and blood pressure in resistant hypertensive individuals: study protocol for a randomized controlled trial. Trials. 2016;17(1):168. doi:10.1186/s13063-016-1302-8

31. Shimizu W, Matsuo K, Kokubo Y, et al. Sex hormone and gender difference-role of testosterone on male predominance in Brugada syndrome. $J$ Cardiovasc Electrophysiol. 2007;18(4):415-421. doi:10.1111/j.1540-8167.2006.00743.x

32. O’Flynn AM, Curtin RJ, Perry IJ, et al. Hypertension prevalence, awareness, treatment, and control: should 24 hour ambulatory blood pressure monitoring be the tool of choice? J Clin Hypertens (Greenwich). 2016;18(7):697-702. doi:10.1111/jch.12737

33. Parati G, Stergiou G, O'Brien E, et al. European Society of Hypertension practice guidelines for ambulatory blood pressure monitoring. J Hypertens. 2014;32(7):1359-1366. doi:10.1097/ HJH.0000000000000221

34. Bressendorff I, Brandi L, Schou M, et al. The effect of high dose cholecalciferol on arterial stiffness and peripheral and central blood pressure in healthy humans: a randomized controlled trial. PLoS One. 2016;11(8):e0160905. doi:10.1371/journal.pone.0160905

35. Lilamand M, Vidal JS, Plichart M, et al. Arterial stiffness and medial temporal lobe atrophy in elders with memory disorders. J Hypertens. 2016;34(7):1331-1337. doi:10.1097/HJH.0000000000000954

36. Omboni S, Posokhov IN, Kotovskaya YV, et al. Twenty-four-hour ambulatory pulse wave analysis in hypertension management: current evidence and perspectives. Curr Hypertens Rep. 2016;18(10):72. doi:10.1007/s11906-016-0681-2

37. Ohara M, Kohara K, Okada Y, et al. Office-based simple frailty score and central blood pressure predict mild cognitive impairment in an apparently healthy Japanese population: J-SHIPP study. Sci Rep. 2017;7:46419. doi:10.1038/srep46419

38. Kristensen S, Schmidt EB, Schlemmer A, et al. The effect of marine n-3 polyunsaturated fatty acids on cardiac autonomic and hemodynamic function in patients with psoriatic arthritis: a randomised, double-blind, placebo-controlled trial. Lipids Health Dis. 2016;15 (1):216. doi:10.1186/s12944-016-0382-5

39. Moreo A, Vallerio P, Ricotta R, et al. Effects of cancer therapy targeting vascular endothelial growth factor receptor on central blood pressure and cardiovascular system. Am J Hypertens. 2016;29 (2):158-162. doi:10.1093/ajh/hpv077

40. Bandy WD, Reese NB. Strapped versus unstrapped technique of the prone press-up for measurement of lumbar extension using a tape measure: differences in magnitude and reliability of measurements. Arch Phys Med Rehabil. 2004;85(1):99-103.

41. Millen AM, Woodiwiss AJ, Norton GR. Post-exercise effects on aortic wave reflection derived from wave separation analysis in young- to middle-aged pre-hypertensives and hypertensives. Eur J Appl Physiol. 2016;116(7):1321-1329. doi:10.1007/s00421-016-3391-1 
42. Wallbach M, Lehnig LY, Schroer C, et al. Effects of baroreflex activation therapy on arterial stiffness and central hemodynamics in patients with resistant hypertension. $J$ Hypertens. 2015;33 (1):181-186. doi:10.1097/HJH.0000000000000361

43. Brunner-La Rocca HP. Towards applicability of measures of arterial stiffness in clinical routine. Eur Heart J. 2010;31(19):2320-2322. doi:10.1093/eurheartj/ehq211

44. Reference Values for Arterial Stiffness' Collaboration. Determinants of pulse wave velocity in healthy people and in the presence of cardiovascular risk factors: 'establishing normal and reference values'. Eur Heart J. 2010;31(19):2338-2350. doi:10.1093/eurheartj/ehq165

45. Vallerio P, Sarno L, Stucchi M, et al. Long-term effects of radiotherapy on arterial stiffness in breast cancer women. Am J Cardiol. 2016;118(5):771-6. doi:10.1016/j.amjcard.2016.06.001

46. Lang RM, Badano LP, Mor-Avi V, et al. Recommendations for cardiac chamber quantification by echocardiography in adults: an update from the American Society of Echocardiography and the European Association of Cardiovascular Imaging. Eur Heart $J$ Cardiovasc Imaging. 2015;16(3):233-270. doi:10.1093/ehjci/jev014

47. Abdalla M, Caughey MC, Tanner RM, et al. Associations of blood pressure dipping patterns with left ventricular mass and left ventricular hypertrophy in blacks: the Jackson Heart Study. J Am Heart Assoc. 2017;6(4):e004847. doi:10.1161/JAHA.116.004847

48. Yuksel IO, Akar Bayram N, Koklu E, et al. Assessment of impact of weight loss on left and right ventricular functions and value of tissue doppler echocardiography in obese patients. Echocardiography. 2016;33(6):854-861. doi:10.1111/echo.13185

49. Wang Y, Shoemaker R, Thatcher SE, et al. Administration of 17beta-estradiol to ovariectomized obese female mice reverses obesity-hypertension through an ACE2-dependent mechanism. Am $J$ Physiol Endocrinol Metab. 2015;308(12):E1066-E1075. doi:10.1152/ajpendo.00030.2015

50. More AS, Mishra JS, Hankins GD, et al. Enalapril normalizes endothelium-derived hyperpolarizing factor-mediated relaxation in mesenteric artery of adult hypertensive rats prenatally exposed to testosterone. Biol Reprod. 2015;92(6):155. doi:10.1095/ biolreprod.114.121095

51. Asmar R. Effects of treatment on arterial stiffness and central blood pressure-points to consider. J. Clin Hypertens (Greenwich). 2015;17 (2):105-106. doi:10.1111/jch.12477

52. Franklin SS, Thijs L, Hansen TW, et al. Significance of white-coat hypertension in older persons with isolated systolic hypertension: a meta-analysis using the International Database on Ambulatory Blood Pressure Monitoring in Relation to Cardiovascular Outcomes population. Hypertension. 2012;59(3):564-571. doi:10.1161/ HYPERTENSIONAHA.111.180653

53. Hermida RC, Ayala DE, Fernandez JR, et al. Hypertension: new perspective on its definition and clinical management by bedtime therapy substantially reduces cardiovascular disease risk. Eur J Clin Invest. 2018;48(5):e12909. doi:10.1111/eci.12909

54. Wu FC, von Eckardstein A. Androgens and coronary artery disease. Endocr Rev. 2003;24(2):183-217. doi:10.1210/er.2001-0025

55. Su JJ, Park SK, Hsieh TM. The effect of testosterone on cardiovascular disease: a critical review of the literature. Am J Mens Health. 2014;8(6):470-491. doi:10.1177/1557988314522642

56. Negro-Vilar A. Selective androgen receptor modulators (SARMs): a novel approach to androgen therapy for the new millennium. $J$ Clin Endocrinol Metab. 1999;84(10):3459-3462. doi:10.1210/ jcem.84.10.6122

57. Schwabbauer ML. Use of the latent image technique to develop and evaluate problem-solving skills. Am J Med Technol. 1975;41 (12):457-462.
58. Bassil N, Alkaade S, Morley JE. The benefits and risks of testosterone replacement therapy: a review. Ther Clin Risk Manag. 2009;5 (3):427-448

59. Miller VM, Mulvagh SL. Sex steroids and endothelial function: translating basic science to clinical practice. Trends Pharmacol Sci. 2007;28(6):263-270. doi:10.1016/j.tips.2007.04.004

60. Harman SM, Metter EJ, Tobin JD, et al. Longitudinal effects of aging on serum total and free testosterone levels in healthy men. Baltimore Longitudinal Study of Aging. J Clin Endocrinol Metab. 2001;86 (2):724-731. doi:10.1210/jcem.86.2.7219

61. Araujo AB, Wittert GA. Endocrinology of the aging male. Best Pract Res Clin Endocrinol Metab. 2011;25(2):303-319. doi:10.1016/j. beem.2010.11.004

62. Jockenhovel F. Testosterone therapy-what, when and to whom? Aging Male. 2004;7(4):319-324.

63. Chignalia AZ, Oliveira MA, Debbas V, et al. Testosterone induces leucocyte migration by NADPH oxidase-driven ROS- and COX2-dependent mechanisms. Clin Sci (Lond). 2015;129(1):39-48. doi: $10.1042 / \mathrm{CS} 20140548$

64. Pearson LJ, Yandle TG, Nicholls MG, et al. Regulation of endothelin-1 release from human endothelial cells by sex steroids and angiotensin-II. Peptides. 2008;29(6):1057-1061. doi:10.1016/j. peptides.2008.02.003

65. Darr R, Bursztyn M, Pamporaki C, et al. Dipping in ambulatory blood pressure monitoring correlates with overnight urinary excretion of catecholamines and sodium. J Clin Hypertens (Greenwich). 2016;18(9):921-926. doi:10.1111/jch.12791

66. Setia S, Subramaniam K, Teo BW, et al. Ambulatory and home blood pressure monitoring: gaps between clinical guidelines and clinical practice in Singapore. Int J Gen Med. 2017;10:189-197. doi:10.2147/ IJGM.S138789

67. Weber MA, Turner JR. Ambulatory blood pressure monitoring: new directions and uncertainties arise from the U. S. Preventive Services Task Force Recommendation on the diagnosis of hypertension. $J$ Clin Hypertens (Greenwich). 2016;18 (3):172-174. doi: $10.1111 /$ jch. 12798

68. Ravenell J, Shimbo D, Booth JN 3rd, et al. Thresholds for ambulatory blood pressure among african americans in the Jackson Heart Study. Circulation. 2017;135(25):2470-2480. doi:10.1161/ CIRCULATIONAHA.116.027051

69. Eichler I, Wibawa J, Grgic I, et al. Selective blockade of endothelial $\mathrm{Ca} 2+$-activated small- and intermediate-conductance $\mathrm{K}+$-channels suppresses EDHF-mediated vasodilation. Br J Pharmacol. 2003;138 (4):594-601. doi:10.1038/sj.bjp.0705075

70. Sartori-Valinotti JC1, Iliescu R, Yanes LL, et al. Sex differences in the pressor response to angiotensin II when the endogenous renin-angiotensin system is blocked. Hypertension. 2008;51 (4):1170-1176. doi:10.1161/HYPERTENSIONAHA.107.106922

71. Reckelhoff JF. Sex steroids, cardiovascular disease, and hypertension: unanswered questions and some speculations. Hypertension. 2005;45(2):170-174. doi:10.1161/01.HYP.0000 151825.36598 .36

72. Chinnathambi V, Yallampalli C, Sathishkumar K. Prenatal testosterone induces sex-specific dysfunction in endothelium-dependent relaxation pathways in adult male and female rats. Biol Reprod. 2013;89(4):97. doi:10.1095/biolreprod.112.106542

73. Vasunta RL, Kesaniemi YA, Ylitalo A, et al. Nondipping pattern and carotid atherosclerosis in a middle-aged population: OPERA Study. Am J Hypertens. 2012;25(1):60-66. doi:10.1038/ ajh.2011.159 


\section{Publish your work in this journal}

Clinical Interventions in Aging is an international, peer-reviewed journal focusing on evidence-based reports on the value or lack thereof of treatments intended to prevent or delay the onset of maladaptive correlates of aging in human beings. This journal is indexed on PubMed Central, MedLine, CAS, Scopus and the Elsevier
Bibliographic databases. The manuscript management system is completely online and includes a very quick and fair peer-review system, which is all easy to use. Visit http://www.dovepress.com/ testimonials.php to read real quotes from published authors. 